\title{
A ESCRITA QUE VAZA. CONEXÕES E ENTRELAÇAMENTOS COM A EXPERIÊNCIA
}

\author{
Fabiane Olegário $^{1}$ \\ fabiji10@yahoo.com.br \\ Angelica Vier Munhoz ${ }^{2}$ \\ angelicavmunhoz@gmail.com
}

\section{RESUMO:}

Neste texto ensaístico temos a intenção de problematizar a formatação da escrita acadêmica erigida através de jogos de poder e saber, os quais legitimam a verdade homogeneizadora das práticas de escrita circuncrevendo o pensamento representacional, visto que este estabelece as formas de ser, de pensar e de viver do sujeito, ao moldar e ao capturar as subjetividades. No embate de forças instítuidas, quais são as possibilidades de constituir a si mesmo, enquanto força instituinte, ativa e propulsora de escrita prenhe de vida? Trata-se, portanto, não de um ensejo prescrito e tampouco de apontar a melhor maneira de escrever, ao contrário, o esforço está na tentativa de conversão do olhar, desestabilizando o modo de ver o familiar, através de experimentações que requerem o exercício permanente, atencioso e transformador de si. Para tal empreendimento, nos aproximamos dos escritos de Clarice Lispector sobre o desejo de experiência da escrita.

Palavras - chaves: escrita, experiência, modos de subjetivação.

This essay aims at problematizing academic writing, which is constructed by means of power and knowledge games that legitimate the homogenizing truth of writing practices and circumscribe the representational thought, thus establishing the subjects' ways of being, thinking and living, by shaping and capturing subjectivities. In the confrontation of instituted forces, what are the possibilities of constituting oneself as an instituting, active and propelling force of living writing? This is neither a prescribed opportunity nor the indication of the best way of writing; rather, this effort is focused on the attempt of a converging look, disestablishing the way of looking at the familial, through experimentations that require permanent, attentive, self-transforming exercise. In order to perform such task, an approximation to Clarice Lispector's writings about the desire for the writing experience has been tried.

Keywords: writing, experience, modes of subjectivation.

Vou criar o que me aconteceu. Só porque viver não é relatável. Viver não é vivível. Terei de criar sobre a vida. E sem mentir. Criar sim, mentir não. Criar não é imaginação, é correr o grande risco de ser e ter a realidade. Entender é uma criação, meu único modo (LISPECTOR, 1994, p.25).

Escolhemos as palavras do romance de Clarice Lispector para puxar a conversa, pois encontramos nelas o mote que precisávamos para iniciar o que propusemos pensar e escrever

\footnotetext{
${ }^{1}$ Mestre em Educação pela Universidade de Santa Cruz do Sul (UNISC). Pedagoga e Psicopedagoga pelo Centro Universitário UNIVATES. Docente no curso de Pedagogia do Centro Universitário UNIVATES e da rede pública estadual.

${ }^{2}$ Doutora em Educação pela Universidade Federal do Rio Grande do Sul (UFRGS). Docente e coordenadora do curso de Pedagogia do Centro Universitário UNIVATES.
} 
no decorrer destas linhas desalinhadas. Assim como Clarice, lançamo-nos ao desafio de correr os riscos possíveis ao parir pensamentos e catar aquilo que foge ao previsível, desencadeando o impensado, produzido pelas coisas miúdas, pequenas, aquelas às quais se atribui pouco ou nenhum valor. Desestabiliza-se assim a ordem da escrita cristalizada, fazendo gaguejar a língua ${ }^{3}$. Ao construir esse começo, procuramos as ferramentas, ao modo foucaultiano, para os possíveis entrelaçamentos com a escrita instituída e com os traços que andam às avessas, desregrados, desmetidos, impuros, desgarrados do território de origem, distante de filiações que rumam ao desconhecido e entregam-se à aventura do acaso, criando um mundo incerto e, todavia, perigoso, pois acompanhando Lispector (1978) “nunca estamos seguros de ser suficientemente fortes, pois não temos sistemas, temos apenas linhas e movimentos" (p.26).

Trata-se de uma escrita que incita a produção da diferença, que segue as linhas arbitrárias, provisórias e passageiras, pois "o processo de escrever é feito de erros - a maioria, essenciais" (Lispector, 1994, p.483) Desterritorializadas, as linhas errantes desequilibram as molaridades, desmancham os modelos que aprendemos a naturalizar, mexendo e remexendo nas certezas já estremecidas pelos fios estáveis da diferença. Mostram a estranheza daquilo que é familiar, dando a ver pela primeira vez, configurando o não identificado, o não reconhecível, o não representado para experimentar outras reconfigurações à escrita, deixando nada além de rastros inusitados.

$\mathrm{Na}$ contramão das regras e dos códigos que definem a verdade, os quais revelam o saber em torno da escrita referendada nos "protocolos normativos entranhados nas rotinas escriturais escolares" (Aquino, 2011 p.647), há palavras que gritam, gemem, balbuciam, gaguejam, torcendo e retorcendo a escrita homogênea. Talvez caiba registrar que não existe oposição de contrários, pois é "sempre possível desfazer os dualismos de dentro traçando a linha de fuga que passa em dois conjuntos, o estreito riacho que não pertence nem um nem outro" (DELEUZE; PARNET, 1998, p. 45).

Tal escrita situa-se longe das polaridades e tampouco de respostas verdadeiras, até porque não se trata da palavra em seu encadeamento linear, mas da capacidade de constestar em suas "franjas" sugerindo outras possibilidades para além do que está posto e instituído. Neste sentido, a escrita, "deixa de estar sobre a jurisdição do "eu" e passa a ser objeto da pulsão, essa força que escapa ao controle” (KRUTZEN, 2008, p.135).

\footnotetext{
${ }^{3}$ Referimo-nos ao texto O que é uma literatura menor? da obra Kafka por uma literatura menor, escrito por Gilles Deleuze e Félix Guattari. Fazer a língua gaguejar, trata-se de escrever em uma língua estrangeira, uma língua que não é sua. A imagem da gagueira permite pensar nos posssíveis da linguagem.
} 
Incita-nos de certo modo, produzir deslocamentos ao olhar, re-significando a escrita compreendida até então, redirecionando para outras perspectivas, a fim de irradiar outras cores, formas e texturas, até tornar-se uma pausa e esvaziar-se do legado que lhe foi imposto pelo significante único. Atitude de suspender a palavra submetida a uma vontade de verdade 4 e configurá-la em um exercício contínuo de escavar a sua força potente, e com isso retirar o sujeito de si mesmo, fazendo que ele não seja mais o mesmo. Escrita grávida pelos fluxos de "potência que é a do fio de metamorfose, um fio que é um vinco, um operador, um fervilhamento, uma linha de fuga, uma dobra" (ORLANDI, 2000 p.63).

Ao fazer referência a uma prática de escrita que se constitui como experiência de si mesmo, que está para além do ideal, aquém do bem e do mal, investimos em suas possibilidades e na sua força de perfurar o instituído acolhendo traços transgressores que se conectam nas franjas e nas margens daquilo que está posto, tecendo outras composições, misturas e movimentos instigadores de criação. Atividade que incita o surgimento de outros possíveis e o apagamento do eu soberano, destituído de característica universal, pois o “sujeito que escreve não pára de desaparecer" (Foucault, 2006, p. 268). Contudo, o objetivo nada mais é que desertar o eu, essa forma dominante de escrever e pensar. Neste sentido, põese em funcionamento sua função política de transformação de si mesmo, ao se desvencilhar das amarras discursivas dominantes.

Resistir, escrevendo anonimamente a fim de subscrever os possíveis. Transgredir o existente da escrita institucional, inventando traços que comportam o novo, fabricado através do contágio com as partículas menores, escavando outras experiências, conexões, cortes e atravessamentos que possibilitam a palavra saltar de pontes. Caminhar com os pés descalços, abrigando a singularidade que reside na superfície da pele, rumo à imprevisibilidade da escrita, abrindo sendas de passagens aos afectamentos que pedem licença. Pequenos murmúrios e balbucios, fazendo vacilar o poder/verdade que constitui o pensamento dogmático da escrita convencional. Miríades de acontecimentos ${ }^{5}$ infames esfarelam o poder, rompendo totalidades e pretensões homogeneizantes em torno da escrita.

\footnotetext{
${ }^{4}$ Trazemos para o texto a vontade de verdade a partir das teorizações nietzschiana. Na esteira de Nietzsche, Roberto Machado em seu livro 'Nietzsche e a verdade' (2002), elucida que "a vontade de verdade, como vontade de moral, está intrinsecamente vinculada à vontade de potência, de um tipo específico que serve à conservação e não a expansão da vida" (p.77).

${ }^{5}$ Referimo-nos ao acontecimento partindo das teorizações de Foucault (2001), que trata do acontecimento não como uma batalha, mas como uma relação de forças que investe em um poder confiscado, entendido como uma
} 
Modos de pensamento sempre em estado de experimentação ganham conteúdo e forma menores ao implicar-se em restos e em sobras, transitam pelas rachaduras, borrando os métodos cartesianos e esfarelando os pensamentos árboreos ${ }^{6}$. Exercícios de torcer as palavras, para então, testemunhar o divórcio entre as palavras e coisas, conectam as palavras nas práticas de experimentação, visto que "não há nada para compreender, nada a interpretar" (DELEUZE; PARNET, 1998, p.12) apenas experimentar.

Os efeitos da imprevisibilidade invertem os sentidos e os objetivos da escrita institucional baseada na representação, provocando outras estratégias para a escrita, traçando seus desvios dentro do próprio caminho que determinam as estruturas unifomes à palavra. Traços encharcados pelos fios da suspeita murmuram que "é preciso torcer o pescoço da eloquência, rejeitando a técnica e desconfiando das palavras" (BLANCHOT, 1997, p.51).

Uma escrita porosa se expressa através de correntes de vontade de criação, com coragem de invenção, liberta-se do aprisionamento selado pelo regime de verdade claudicando a escrita modelo. Escrita que arranca o sujeito para fora de si, fazendo dele um estangeiro de si mesmo, pois "escrever e pensar nos separa de nós mesmos das nossas origens, de nossas heranças, morremos um pouco" (Fischer, 2005, p.131), possibilitando “breves e meteóricas aparições de nós mesmos". (Idem, p.121)

A fim de reforçar o coro, trazemos as palavras de Corazza (2006), pois nesta perspectiva “[...] as mãos que escrevem não são dele [do sujeito] nem de ninguém, muito menos de algum autor que nada mais é do um sujeito inventado. Elas escrevem uma escrita anônima, despersonalizada" (p.28). Tudo indica que há uma relação com a escrita e o esvanecimento do sujeito, visto que se "manifesta no desaparecimento das características individuais do sujeito que escreve" (FOUCAULT, 2006, p.269).

Neste sentido, com as chances de compor outros cenários inseparáveis da vida, da invenção, da experimentação para a escrita, encontramos nas palavras de Clarice, a escrita bailarina $^{7}$, pois nos parece que traduz intensamente o desafio de assinar com o nome próprio o

dominação que se enfraquece, se distende e se envenena. O acontecimento está para o impensável, o imprevisível que se inscreve nos desvios e nos acidentes.

${ }^{6}$ Deleuze e Guattari (1995) em 'Mil Platos' anunciaram que “estamos cansados da árvore. Não devemos mais acreditar em árvores, em raízes ou radículas, já sofremos muito”. (p.25). Utilizam a metafóra botânica para expressar uma ideia, para criar um conceito, rizoma contrapondo o modelo árboreo de pensamento.

${ }^{7}$ O uso da expressão partiu do texto 'Clarice Lispector: a escrita bailarina', escrito por Daniel Lins. Ver referências. 
pulsar da existência. "Se eu fosse eu""8 quais seriam os possíveis que habitam o eu fazendo dele outro? A vontade de outrar-se no pensamento é também vontade de outra escrita, entrelaçada pelas linhas de fuga ${ }^{9}$, fazendo vazar o sistema instituído decodificando e desterritorializando a escrita acadêmica, dando passagem aos fluxos da experiência.

Mas bem sei o que quero aqui [...] quero a experiência de uma falta de construção. Embora este meu texto seja todo atravessado de ponta a ponta por um frágil fio condutor - qual? O de mergulho na matéria da palavra? O da paixão? Fio luxurioso, sopro que aquece o decorrer das sílabas. (Lispector, 1978, p.15)

Pelo exposto, escolhemos alguns excertos de Clarice para compor este ensaio. Tudo indica que seus textos foram experiências do seu pensamento, escritos com sangue e com todo o corpo. As palavras que compunham o enredo dos seus romances e crônicas tocam o inexpressivo, pois para ela, "a pior arte é a expressiva, aquela que transgride o pedaço de ferro e o pedaço de vidro, e o sorriso, e o grito" (LISPECTOR, 1994 p.144).

A obra de Clarice nos faz pensar na escrita que modifica a relação com nós mesmos, devido à força potente que transforma o sujeito em outro, no desconhecido de si, e que passa a interferir nos modos de pensar e de viver, aumentando a capacidade de afectar e ser afectado por forças ativas e afirmadoras da vida. Viver a escrita e a vida como uma experiência é permitir que outras vozes nos acometam, escrevendo por nós, pois, engendra um movimento de sair de si mesmo, para criar o desconhecido, provocando rupturas na forma representantiva de ser a fim de "sair de si, rumo ao exterior viagem e aventura fora de si, inspeção da exterioridade" (CHAUÍ, 2002 p.161).

A escrita parida nos fluxos da experiência se opõe à categorização, à classificação do pensamento e à subordinação de forças reativas, visto que deixa o território da representação para se tornar experimento, que afirma a imanência de uma vida. Rejeitar um mundo transcendente, escapando das formas dominantes de escrever, possibilita seguir interrogando e estranhando a verdade que rege e formata a escrita, instalando outros espaços para a constituição de si. Como não é possível estar fora das relações de poder e saber de modo sóbrio e criativo, a experiência aposta nas forças do lado de fora do pensamento, reino do

\footnotetext{
8 Título da crônica de Clarice Lispector retirado da coletânea Clarice na Cabeceira, organizado por Teresa Montero e publicado pela Rocco, 2010, em que ela escreve "Experimente: se você fosse você, como seria e o que faria?" (p.81).

${ }^{9}$ No sentido deleuziano, "o grande erro, o único erro, seria acreditar que uma linha de fuga consiste em fugir da vida; a fuga para o imaginário ou para arte. Fugir, ao contrário, é produzir algo real, criar uma vida, encontrar uma arma." (Deleuze; Parnet, 1998, p.62).
} 
devir e das tempestades de forças, zona de turbulência, onde as coisas ainda não são, mas tudo está por acontecer, pois "nos mobiliza e nos faz tremer a voz e as vísceras, o olhar" (FISCHER, 2005, p. 121).

Foucault (2010) sublinhava ser um experimentador no sentido em que escrevia para mudar a si mesmo e não mais pensar na mesma coisa de antes, pois as "forças descontínuas, espamódicas, dispostas apenas ao encontro com a diferença” (Aquino, 2011, p.654), desfazem o sentido único, proporcionando a liberação do pensamento como potência criadora e

afirmativa da vida, compondo o coro com Zaratustra ${ }^{10 .}$

Concordando com Larrosa (2002), a experiência requer tempo para pensar, olhar, escutar, sentir e silenciar. Neste sentido, também implica pensar que não se trocam experiências como se trocam as figurinhas de um álbum, já que consiste em um exercício que opera nas singularidades, exercitando cada molécula do corpo.

\begin{abstract}
A experiência é o que nos passa, o que nos acontece, o que nos toca. Não o que se passa, não o que acontece, ou o que toca. A cada dia se passam muitas coisas, porém ao mesmo tempo, quase nada nos acontece [...] nunca se passaram tantas coisas, mas a experiência é cada vez mais rara. (p.21)
\end{abstract}

Os fluxos que conjugam os territórios da experiência procuram agenciar-se ao tempo para, então, conquistar a demora que permite ao olho ver os ínfimos detalhes. Tempo para prender o olho no pequeno, naquilo que não costumamos ver. Tempo para desarrumar a casa, para dispor de novas combinações. Efeitos de um tempo contemporâneo, a experiência é prejudicada pelas marcas do efêmero que constituem a vida instantânea, fazendo com que nada nos aconteça. Tempo acelerado que restringe e cancela a possibilidade de experienciar.

Escrevo em signos que são mais um gesto que voz [...] $\mathrm{O}$ mundo não tem ordem visível e eu só tenho ordem da respiração. Deixo-me acontecer. (LISPECTOR, 1978, p.24)

Um ensaio para a vida e para a escrita. Inseparabilidade. Ambas se nutrem e se potencializam mutuamente. Escrever para fazer nascer o que ainda não existe, ao invés de representar o já dado. Escrita maquinada por afectos, encontros, aligeirada pela vontade de criação. Escrita tecida por agenciamentos, devires e conjugações menores. Escrita artista que

\footnotetext{
${ }^{10}$ Zaratustra é o personagem conceitual de Nietzsche, o sim de Zaratustra se opõe ao não dialético. Uma força afirmativa da vida em que pulsa a diferença, já que é ativa nega tudo aquilo que ela não é e faz desta negação a tessitura da própria criação. Friedrich Nietzsche em sua obra Assim falou Zaratustra, trata da trajetória do personagem e de ideias importantes, tais como o eterno retorno e a vontade de potência.
} 
ensaia as palavras de um pensamento que está na corda bamba. Feita de silêncios, gritos e murmúrios, coloca em dúvida o próprio pensamento. Descontínuos movimentos, desalinhos que possibilitam "à linguagem deixar de ser representativa para tender para seus extremos ou seus limites" (DELEUZE; GUATTARI, 1977, p.36).

Como modo de experimentação do pensamento, a filosofia deleuziana aposta no pensamento rizomático para desarticular a lineariedade e desmanchar os inícios e os fins, pois o que importa são os meios. Movimento que não começa, nem finda, que encontra no meio a velocidade potente, pois o "real não está na saída nem na chegada, ele dispõe para a gente no meio da travessia" (GUIMARÃES, 2001, p.52).

Ao experimentar a escrita, o pensamento adquire velocidade no seu meio ao realizar outras conexões, bifurcações e construções de trajetos, sobretudo, porque ousa subverter o caminho previsto. Contrariando o percurso baseado na linearidade, a experimentação articulase às andanças rizomáticas, pois possibilita novas e inesperadas direções ao pensamento que dança com as palavras, pois como escrevem Deleuze e Guattari (2002) "a mesma coisa, a mesma palavra, tem sem dúvida essa dupla natureza: é preciso extrair uma da outra transformar as composições de ordem em componentes de passagens”. (p.59)

Pensar e escrever se configura em um exercício de experimentação que dobra, desdobra e redobra as forças, incitam à criação de partículas novas visto que, quando uma escrita é tomada por encontros e composições imprevisíveis, um tanto se põe a escorrer: identidade, representação e racionalidades puras deixando em suspensão "o que éramos, o que somos e o que pensávamos" (CORAZZA, 2005, p.19).

Escrita de intensidade molecular que se agita em pontos singulares, compondo trajetórias e modulações deslizantes. Constitutem ínfimas e inefáveis metamorfoses, as quais carregam os pensamentos às terras férteis provocando devires à língua maior. Pensamentos que dão novas crias às experiências menores de escrita, desmanchando modelos ao traçar linhas moleculares à existência, pois, "escrever não tem a ver com significar, mas agrimensurar, cartografar, mesmo que sejam regiões por vir" (Deleuze; Guattari, 1995, p.13); tem a ver com o corpo, com o pensamento em movimento de experimentação de outros modos singulares de existência.

Escrita que é parida pelo acontecimento, expondo as palavras em variação atendendo os sentidos menores, minando as práticas institucionais, engessadas pelos códigos representacionais que tratam de uniformizar a linguagem escrita ao regular e normatizar o padrão para escrever. Silenciando o sistema, provocando variações na linguagem em favor de um escrito experimento. 
Desestruturar a escrita formal não tem a ver com destruí-la, reduzi-la a nada, levandoa a fogueira. A intenção é fazê-la vibrar, pulsar, gritar elevando ao máximo a sua potência de criação, a qual opera dentro das linhas molares da língua, pois "não se faz a coisa com pancadas de martelo, mas com uma lima muito fina" (Deleuze; Guattari, 1999, p.22). Desse modo, a experimentação escrita e seus usos menores não desqualificam e não negam a existência da língua maior, até porque as possibilidades de criação estão implicadas e emaranhadas entre uma e outra.

Escrita - pensamento - vida como uma possibilidade de "obra de arte, regras ao mesmo tempo éticas e estéticas que constituem modos de existência ou estilos de vida" (Deleuze, 1992, p.123), que podem “irromper daí resistências inéditas e vozes inauditas, aptas a dobrar-nos diferentemente" (Perbalt, 2000, p. 62). Em outras palavras, ter a escrita como possibilidade de subversão ao modelo representacional de escrita, atitude menor que está sempre em relação à escrita maior. Escrever implica em correr riscos, pois nunca se sabe o que espera cada traço. Escrita que diz respeito à vida, que é da ordem da imprevisibilidade, pois “pensar e ser são uma coisa só” (DELEUZE; GUATTARI, 1996, p.34).

Pensamento nas 'dobras' que borra as fronteiras, profanando o ideal de escrita, esparrama-se nas linhas provisórias, desalojando as certezas e os códigos representativos que uniformizam a escrita institucionalizada (dura). Rasuram a forma única da palavra, abrindo caminho para um novo lugar a ser preenchido por outro modo de escrever $e$ pensar $e$ viver, possibilitando várias maneiras de ensaiar o pensamento, a leitura e a escrita.

Nesta perspectiva,

[...] o trabalho da escrita se confunde com o de viver ou, mais precisamente, com um modo intensivo de conduzir a sua própria existência. Escrever constitiria, assim, numa experiência de transformação do que se pensa, e acima de tudo, do que se é; uma experiência avessa, ademais, a qualquer apelo comunicativo ou normativo (Aquino, 2011, p.644).

Assim, a escrita como modo de experimentação do pensamento exige, do sujeito que escreve, a constituição para si de outras invenções de práticas de liberdade, problematizando os ditos e os escritos em torno da verdade de uma suposta ordem institucionalizadora e normalizadora das palavras. Neste jogo de suspensão, os códigos são embaralhados, produzindo outros arranjos e procedimentos menores às palavras.

A composição de outros territórios possíveis consiste talvez no esforço permanente do olhar atento a si mesmo, no sentido de conduzir-se não permitindo a clausura do pensamento 
dominante que concentra "imperativos pedagógicos que sustentam os automatismos escriturais" (Aquino, 2011, p.653).

Tal proposição talvez tenha seu interesse em uma escrita artista, assim como escreve Corazza (2006).

\begin{abstract}
A escrita-artista não é nunca simples. Ela não normatiza, não representa, não conta história, não ilustra, nem narra o que se passou. Algo passa por ela [...] o escritorartista é um faxineiro: ele esvazia, raspa, escova, limpa. Ele escreve sobre os códigos, palavras de ordem, regimes de signos, para rechaçá-los embaralhá-los, subvertê-los. No entanto, ele distingue o que lá pulula: aquilo que favorece a escrita, o que a obstaculiza, aquilo que a bloqueia, o que deixa passar intensidades (p.35)
\end{abstract}

Ressaltamos, de maneira antecipada, que não intencionamos responder aquilo que perturba. E a partir desta afirmação, aparentemente descompromissada, aproveitamos para salientar que entendemos a escrita artista ao inverso do sentido utilitário e totalitário, automatizado e reprodutor da escrita que informa e que comunica. Parece-nos que o que importa é a atitude de "deixar para trás a busca muitas vezes obsessiva por vozes e verdades 'interiores', abrindo a quem sabe aos vazios que circulam entre as palavras, entre muitas coisas ditas, aos murmúrios que continuamente desfazem esses vazios" (FISCHER, 2005, p.133).

Por todos estes aspectos, só sobraram às incertezas que se apresentam no decorrer da trajetória a todos aqueles que se arriscam a viver sob a linha feiticeira. Encorajados a correr riscos de desaprender o aprendido, "fabricam o que ainda não existiu nem existe" (Corazza, 2009, p.120). Trata-se, no entanto de um não saber clariciano, de forças intempestivas que furam e que cortam, fazendo o corpo sussurar, pois não tinham sido "pensamentos de cabeça, eram do corpo" (LISPECTOR, 2009, p.143).

\title{
REFERÊNCIAS - Ideias forças
}

AQUINO, Julio Groppa. A escrita como um modo de vida: conexões e desdobramentos educacionais. Educação e Pesquisa. São Paulo, v.37, n.3, set/dez 2011. p.641-656.

BLANCHOT, Maurice. A parte do fogo. Rio de Janeiro: Rocco, 1997.

CHAUÍ, Marilena. Obra de arte e filosofia. IN: Experiência do pensamento.

Ensaios sobre a obra de Merleau - Ponty. São Paulo: Martins Fontes, 2002, p.151-195.

CORAZZA, Sandra. Uma vida de professora. Ijuí: Unijuí, 2005. 
CORAZZA, Sandra Mara. Artistagens: filosofia da diferença e educação. Belo Horizonte: Autêntica, 2006.

CORAZZA, Sandra Mara. Currículos da diferença: somos transmissores de vida. Diálogos na Contemporaneidade. Vertingens do Tempo. IN: SCHUCK, Rogerio (org.) Lajeado: Univates, 2009, p.109-132

DELEUZE, Gilles. Conversações. Rio de Janeiro: Editora 34, 1992.

DELEUZE, Gilles; GUATTARI, Félix. Kafka: Por uma literatura menor. Rio de Janeiro: Imago, 1977.

DELEUZE, Gilles; GUATTARI, Félix. Mil Platôs: Capitalismo e Esquizofrenia. v.1. Rio de Janeiro: Editora 34, 1995.

DELEUZE, Gilles. ; GUATTARI, Félix. O que é filosofia? Rio de Janeiro: Editora 34, 1996.

DELEUZE, Gilles; PARNET, Claire. Diálogos. Tradução: Eloísa Araújo Ribeiro. Rio de Janeiro: Escuta, 1998.

DELEUZE, Gilles; GUATTARI, Félix. Mil Platôs: Capitalismo e Esquizofrenia. v.3. Rio de Janeiro: Editora 34, 1999.

DELEUZE, Gilles; GUATTARI, Félix. Mil Platôs: Capitalismo e Esquizofrenia. v.2. Rio de Janeiro: Editora 34, 2002.

FOUCAULT, Michel. O que é um autor? In:____.Ditos e Escritos III: Estética, Literatura e Pintura. 2. ed. Rio de Janeiro: Forense Universitária, 2006. p.264-298

FOUCAULT, Michel. Conversa com Michel Foucault. In: . Ditos e Escritos VI. Repensar a política. Rio de Janeiro: Forense Universitária, 2010, p.289-347

FISCHER, Rosa Maria Bueno. Escrita Acadêmica: a arte de assinar o que se lê. In: COSTA, Marisa; BUJES, Maria; (Orgs.) Caminhos Investigativos III. Riscos e Possibilidades de Pesquisar nas fronteiras. Rio de Janeiro: DP\&A, 2005. p. 117-140.

GUIMARÃES, Rosa. Grande Sertão: Veredas. Rio de Janeiro: Nova Fronteira, 2001.

KRUTZEN, Eugênia Correia. Discurso e autoria: a escrita terapêutica. Cartografias de Foucault. VEIGA-NETO, Alfredo, FILHO, Alipio de Souza, JÙNIOR, Durval Muniz de Alburquerque (Orgs). Belo Horizonte: Autêntica, 2008. p.123-137

LARROSA, Jorge. Notas sobre a experiência e o saber da experiência. Revista Brasileira de Educação. Rio de Janeiro. n. 19, 2002, p.20-28. 
LINS, Daniel. Clarice Lispector: a escrita bailarina. Corpo, Arte e Clínica. IN: FONSECA, Tania Galli, ENGELMANN, Selda.Porto Alegre: UFRGS, 2004. p.147-160

LISPECTOR, Clarice. Água Viva. Rio de Janeiro: Nova Fronteira, 1978.

LISPECTOR, Clarice. A paixão segundo G.H. 16.ed. Rio de Janeiro: Francisco Alves, 1994.

LISPECTOR, Clarice. Se eu fosse eu. Clarice na cabeceira: crônicas. IN: MONTERO, Teresa (Org). Rio de Janeiro. Rocco. 2010. p.81-82

LISPECTOR, Clarice. A bela e a fera ou a ferida grande demais. Clarice na cabeceira: crônicas. IN: MONTERO, Teresa (Org). Rio de Janeiro. Rocco. 2009. p.135-137

MACHADO, Roberto. Nietzsche e a Verdade. São Paulo: Graal, 2002.

O’ LEARY, Timothy. Foucault, Experiência, Literatura. Tradução Lisa Gertrum Becker não publicada para fins didáticos. Foucault Studies, n5, 2008. p.05-25. Disponível em: < http://www0.hku.hk/philodep/to/TO >FoucStuArt2008.pdf. Acesso em 01 mar.2012.

ORLANDI, Luis B. L. Linhas de ação da diferença. Gilles Deleuze: uma vida filosófica. ALLIEZ , Eric (org.) São Paulo: Ed. 34, 2000, p.49-63.

PELBART. Peter Pál. Fala dos confins: O lugar da literatura na obra de Foucault. Cult: Revista Brasileira de Cultura. São Paulo, abril, nº 134, 2009. p. 50-54. 